\title{
LOOKING FOR MULTIPLE EQUILIBRIA WHEN GEOGRAPHY MATTERS: GERMAN CITY GROWTH AND THE WWII SHOCK
}

\author{
MAARTEN BOSKER \\ STEVEN BRAKMAN \\ HARRY GARRETSEN \\ MARC SCHRAMM
}

CESIFO WORKING PAPER No. 1553

CATEGORY 10: EMPIRICAL AND THEORETICAL METHOdS

SEPTEMBER 2005

An electronic version of the paper may be downloaded

- from the SSRN website:

www.SSRN.com

- from the CESifo website: www.CESifo-group.de 


\title{
LOOKING FOR MULTIPLE EQUILIBRIA WHEN GEOGRAPHY MATTERS: GERMAN CITY GROWTH AND THE WWII SHOCK
}

\begin{abstract}
Many modern trade and growth models are characterized by multiple equilibria. In theory the analysis of multiple equilibria is possible, but in practice it is difficult to test for the presence of multiple equilibria. Based on the methodology developed by Davis and Weinstein (2004) for the case of Japanese cities and WWII, we look for multiple equilibria in a model of German city growth. The strategic bombing of Germany during WWII enables us to assess the empirical relevance of multiple equilibria in a model of city-growth. In doing so, and in addition to the Davis and Weinstein framework, we look at the spatial inter-dependencies between cities. The main findings are twofold. First, multiple equilibria seem to be present in German city growth. Our evidence supports a model with 2 stable equilibria. Second, the explicit inclusion of geography matters. Evidence for multiple equilibria is weaker when spatial interdependencies are not taken into account.
\end{abstract}

JEL Code: R11, R12, F12.

Maarten Bosker
Utrecht School of Economics
Utrecht University
Vredenburg 138
3511 BG Utrecht
The Netherlands
M.Bosker@econ.uu.nl
Harry Garretsen
Utrecht School of Economics
Utrecht University
Vredenburg 138
3511 BG Utrecht
The Netherlands
H.Garretsen@econ.uu.nl

\author{
Streven Brakman \\ Department of Economics \\ University of Groningen \\ P.O. Box 800 \\ 9700 AV Groningen \\ The Netherlands \\ s.brakman@rug.nl \\ Marc Schramm \\ Utrecht School of Economics \\ Utrecht University \\ Vredenburg 138 \\ 3511 BG Utrecht \\ The Netherlands
}

We would like to thank Donald Davis, Jan Jacobs, Jan Oosterhaven and David Weinstein for discussions and suggestions and Steven Poelhekke and Peter Koudijs for research assistance. Please address all correspondence to H.Garretsen@econ.uu.nl. 


\section{Introduction}

One of the central characteristics of New Economic Geography (NEG) models is the presence of multiple equilibria. Ever since the pioneering work of Krugman (1991) this has been one of the fundamental insights of this literature. Especially the theoretical analysis of multiple equilibria has made impressive progress. The early models of the NEG literature relied on numerical analyses, but since the work of Puga (1999) and Fujita, Krugman, and Venables (1999), who introduced the break and sustain analysis of equilibria, analytical results became possible. Given the prevalence of multiple equilibria in not just the NEG models but in many modern trade and growth models, it is remarkable that empirical research into the existence of multiple equilibria is almost completely absent. Davis and Weinstein (2004) are among the first to test for the presence of multiple equilibria in a NEG setting. Their study is a sequel to Davis and Weinstein (2002). In the latter they analyse for the case of Japan whether or not a large and temporary shock like the WWII bombing affected the relative growth of cities in the post war period. They find that this is not the case. This conclusion also holds, to some degree, for the case of (western) German cities and the WWII shock, as is shown by Brakman, Garretsen, and Schramm (2004). Head and Mayer (2004, p.2662) observe, on the basis of these two studies that "...it is tempting to conclude that the greater the constraint imposed by physical Geography, the greater will be the tendency for shocks to undo themselves over time." This also suggests that the real world is not characterized by multiple equilibria, and that the possibility of multiple equilibria should at best be characterized as "theoretical exotica".

Based on the findings of these two papers such a pessimistic conclusion about the empirical (ir)relevance of multiple equilibria is, however, perhaps drawn too soon (see also Gabaix and Ioannides. 2004). First, it is important to note that the standard Krugman (1991) NEG model only predicts a "switch" to a new equilibrium for certain ranges of the key parameters. So the evidence of persistence in the evolution of city sizes after an exogenous shock can still be consistent with a NEG model. The absence of finding empirical evidence of multiple equilibria does not necessarily reject these models as such. Second, and most important for this paper, before dismissing the possibility of multiple equilibria we should test this possibility explicitly. The latter is exactly what Davis and Weinstein (2004) set out to do for Japan. They develop an 
innovative method that examines necessary conditions for multiple equilibria for the case of Japanese city growth and the WWII shock. A rejection of these necessary conditions would be a more powerful rejection of the presence of multiple equilibria than the implicit rejection in Davis and Weinstein (2002). ${ }^{2}$

Their methodology can, however, be criticised for the fact that it does not include geography or location. Davis and Weinstein (2004) assume that the evolution of city shares is independent of the evolution of other city shares. This assumption is at odds with another fundamental characteristic of NEG models. That is, the evolution of the city-size of an individual city depends on the attractiveness of this city relative to the attractiveness of other cities. In this paper we not only apply the methodology developed by Davis and Weinstein (2004) to the strategic bombing of German cities during WWII, but also include geography explicitly in our test. In doing so, our approach is more in line with the standard NEG models. It turns out that the inclusion of geography is important, and contributes fundamentally to our positive evidence for multiple equilibria for our sample of German cities.

In section 2 we will present theoretical background information on multiple equilibria, and illustrate this graphically. Section 3 describes the extent of the destruction of German cities during WWII. It motivates that this constitutes a large exogenous shock to the German city size distribution that is large enough to reveal multiple equilibria if these are present. Section 4 describes the empirical methodology. The data and our findings are described in section 5. It is shown that geography is very important for our results. Section 6 concludes.

\section{Theoretical Background}

A central feature of many modern trade and growth models is that they have multiple equilibria. This is also true for the new economic geography literature, the attempt by mainstream economics to (re-) introduce the role of geography into economics. Following the seminal work by Krugman (1991), new economic geography models

\footnotetext{
${ }^{2}$ Note that their approach differs from that of Redding et al. (2005), who use an extended gravity model approach. Redding et al. (2005) analyze the location of main airport hubs. They find evidence that after the split of Germany into East and West Germany Berlin was not able to hold its position as main airport hub; Frankfurt became the main airport. After the reunification this relative position did not change. According to the authors this is evidence that the equilibrium changed.
} 
endogenize the location decisions of mobile firms and workers and typically display multiple equilibria. Figure 1 illustrates this for the Krugman (1991) model with 2 regions that serves as a benchmark in the analysis of Davis and Weinstein (2004).

Figure 1 Multiple equilibria in the Krugman (1991) model.

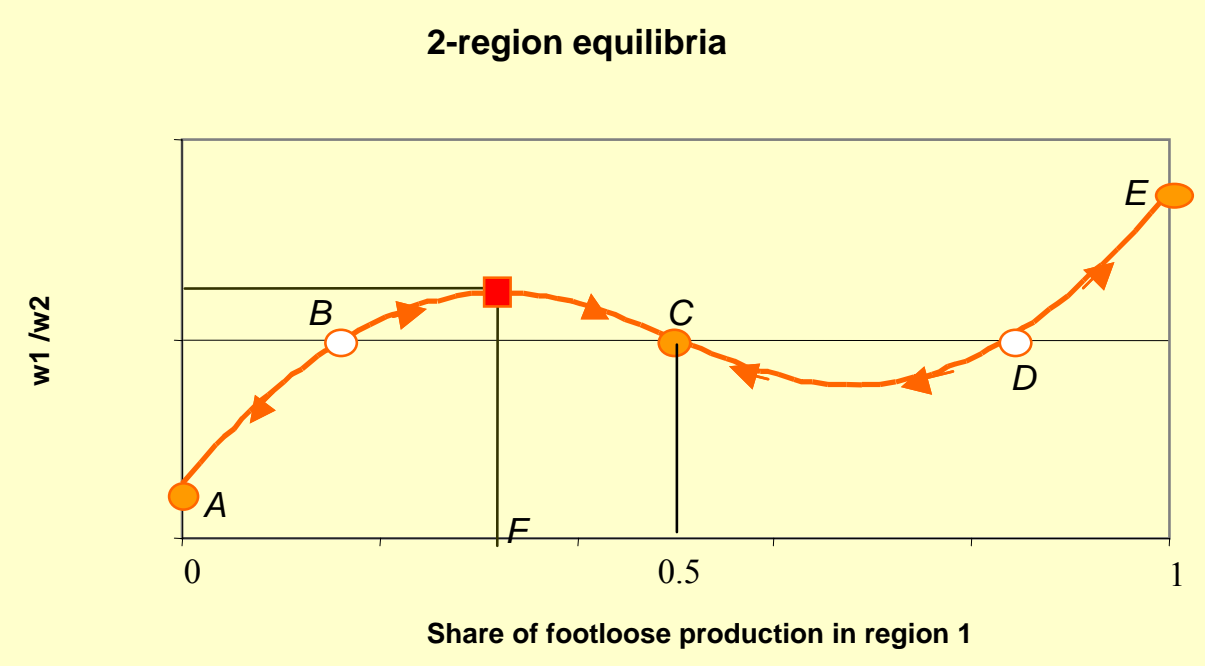

The curve in Figure 1 depicts the equilibrium allocation of the footloose production between the 2 regions. Each point on the curve represents a short-run equilibrium where for a given allocation of the footloose production, factor and goods markets in the 2 regions clear. In the long run, the share of footloose production is no longer given but becomes an endogenous variable (this is really the hallmark of the Krugman model). In the long run we have an equilibrium when the footloose factors do no longer have an incentive to re-locate (in Figure 1 there are 5 such long run equilibria, A-E). Along the horizontal axis the share of the footloose production in region 1 is depicted, which ranges from zero (no footloose activity in region 1) to one (all footloose activity concentrated in region 1). The footloose sector is the manufacturing sector, and its share of manufacturing labour force depicts a region's share of footloose production. The other sector is assumed to be tied to a region (agriculture), that is to say its workers are immobile, and this has the function that there is always a residual demand in the peripheral region, even if the footloose labour force is completely concentrated in the 
other region. This prevents the model from collapsing into a single region model. The vertical axis in Figure 1 gives the ratio of real wages between region 1 and $2, \mathrm{w}_{1} / \mathrm{w}_{2}$. In the basic Krugman (1991) model workers migrate if real wages in the other region are higher. Real wage equality indicates a long run equilibrium; no worker has an incentive to migrate. Figure 1 gives three of these equilibria, B, C, and D where B and D are unstable equilibria. If a mobile worker moves away from equilibria like $\mathrm{B}$ or $\mathrm{D}$, either to region 1 or 2 , other workers will follow. $\mathrm{C}$ is a stable equilibrium, if a worker would relocate real wages will change in such a way that she has an incentive to return. Complete agglomerations, equilibria $\mathrm{A}$ and $\mathrm{E}$ are also stable equilibria (although the concept of the ratio of real wages is hypothetical here-there are no footloose workers in the other region to compare wages).

The arrows along the curve point towards the stable equilibria in this model and show in which direction migration takes place. If the economy finds itself in a point like $\mathrm{F}$, where $w_{1}>w_{2}$ migration of footloose workers from region 2 to region 1 will ensure that we end up in the stable symmetric equilibrium $\mathrm{C}$. The analysis of agglomerating and spreading forces that leads to figures like Figure 1 is well-known and we do not dwell on this any further here. ${ }^{3}$ As is also emphasized by Davis and Weinstein (2004), extensions of the Krugman (1991) model also allow for asymmetric stable equilibria where one ends up with partial agglomeration. For our present purposes and in terms of Figure 1, we want to emphasize that for an interior equilibrium like $\mathrm{C}$ (that is an equilibrium without complete agglomeration), to be stable we need a negative slope and the unstable equilibria (here, B and D) can be looked upon as thresholds when we pass from one stable equilibrium to another stable equilibrium.

For our present purposes the point to emphasize is that Figure 1 shows that multiple equilibria are a central characteristic of the Krugman (1991) model. Given the assumption that the economy is initially in a stable equilibrium, a relocation or shock to the footloose labour force can in theory have two implications for the long run equilibrium. The shock is small and workers return to their original location that is to say to the initial stable equilibrium, or the relocation is large enough to pass the

\footnotetext{
${ }^{3}$ For a more extensive discussion of the Krugman (1991) model see Fujita, Krugman, Venables (1999), Brakman, Garretsen, van Marrewijk (2001), Fujita and Thisse (2002) or Baldwin et al (2003). Introducing additional (spreading) forces into this model increases the number of long-run equilibria (Brakman, Garretsen, Van Marrewijk, and Van den Berg (1999) and in particular opens the way to asymmetric, stable equilibria that is stable equilibria with partial agglomeration.
} 
threshold of the nearest unstable equilibrium and the economy moves to another stable equilibrium. Following Davis and Weinstein (2004) we can represent this adjustment process in a two period growth space as depicted in Figure 2. In order to facilitate comparison we stick to their use of symbols from hereon. To make the transition from the Krugman (1991) model to cities and city-growth, we replace a region's share in the footloose labour force as our main variable of interest by the (log-) share of a city $i$ in the total population, denoted by $S_{i}$ (where we can suppress the subscript $i$ since all cities are assumed to be alike in terms of their reaction to a particular city-specific shock of a given size, this is clearly an important (and restrictive) assumption as it means that the model underlying Figure 2 is based on the notion of a representative city). ${ }^{4}$

Figure 2. Two-period growth representation of a model with 3 stable equilibria

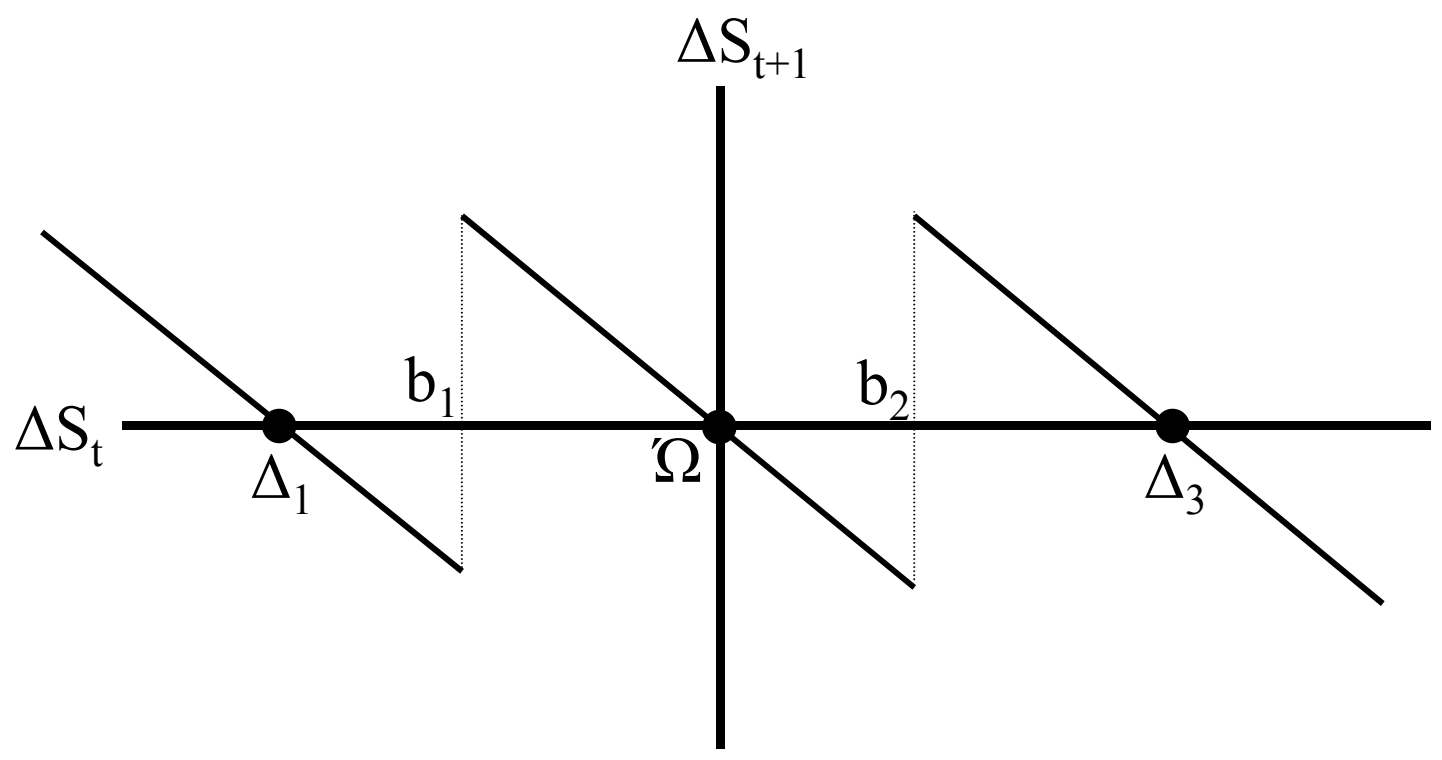

Let $\Omega$ indicate the initial stable equilibrium and let $\Delta_{1}$ and $\Delta_{3}$ depict two surrounding stable equilibria. If a shock that hits a city is too small to pass the thresholds $b_{1}$ or $b_{2}$ the city share will return to the initial equilibrium, implying that the second period change will completely and precisely undo the shock. This is indicated by the line through the

\footnotetext{
${ }^{4}$ Note that using log-shares, reformulates the model in growth rates. This facilitates the empirical analysis. Furthermore, Figure 2 thus indicates that each region or city has the same response to the same shock. A shock of size $\mathrm{X}$ that changes the equilibrium for city A does the same for region or city B. Another important innovation of Davis and Weinstein (2004), as compared to Davis and Weinstein (2002), is that they do not only model city growth in terms of city population but also in terms of economic activity, the change of manufacturing activity across Japanese cities. We return to this in section 5.4.
} 
origin with a slope of minus unity. The period $t$ is the period that includes the shock and the period $t+1$ is the period in which the effects of the shock are precisely undone, hence the slope of -1 (Davis and Weinstein, 2004, p. 7). For an equilibrium to be stable it must the case in this 2 period growth set-up that there exists a period $t+1$ that is long enough such that $\Delta S_{t}=-\Delta S_{t+l}$. To see this, return to Figure 1, and assume that starting from the initial, stable equilibrium $\mathrm{C}$ a shock occurs in period that moves the economy to point $\mathrm{F}$. It may take a while, that is period $t+1$ can be quite long, but ultimately the economy will have to return to point $\mathrm{C}$ which means that the effect of a shock at period $t$ is exactly off-set in period $t+1$. It is an empirical matter if the time series for $\mathrm{t}+1$ are long enough to include a point like $\mathrm{C}$. So in practice the slope could be less than 1 (in absolute terms). We will return to this issue in section 5 .

If the shock is large enough to move the city's population share outside the range $b_{1}-b_{2}$, a new stable equilibrium will be established and the economy will move to $\Delta_{1}$ or $\Delta_{3}$ depending on whether the city is hit by a negative or positive shock. But each new stable equilibrium it must also be true in our 2 period setting that $\Delta S_{t}=-\Delta S_{t+1}$. For the example of 3 stable equilibria of Figure 2 these two possibilities are indicated by the two solid lines through $\Delta_{1}$ and $\Delta_{3}$ also with a slope of minus unity. ${ }^{5}$ To sum up, in case of multiple equilibria we end up in the two period growth setting of Figure 2 with a sequence of negative sloped lines with slope minus unity, where each line corresponds to a different stable equilibrium.

Our difference with the Davis and Weinstein (2004) set-up is that we do take spatial interdependencies into account. What happens to a particular city following the shock could in princple also be determined by the shock that hit other cities. In other words, in our empirical strategy to test the model underlying Figure 2 we assume that $\Delta S_{t+1, i}=f\left(\Delta S_{t, i}, \Delta S_{t, j \neq i}\right)$, where besides the time subscript, $t$, we also include a region or city subscript, $i, j$. The reason can most easily be understood by looking once more at Figure 1. One of the essential insights from new economic geography literature is that

\footnotetext{
${ }^{5}$ For an equilibrium to be stable there always must exist a period $t+1$ that is long enough so as to ensure that the slope will be minus unity. So from a theoretical perspective our translation of a new economic geography model like Figure 1 (the Krugman (1991) model) in the 2 period growth space of Figure 2 gives a foundation for a slope of minus one in $\left(S_{t}, S_{t+1}\right)$ space. This will turn out to be important for the empirical testing of the model underlying Figure 2. From this theoretical perspective any other slope than -1 in Figure 2 is hard to justify if the sample period for $\mathrm{S}_{\mathrm{t}+1}$ is long enough.
} 
regions or cities should not be analysed in isolation, but relative to other regions. It is the relative position of one region to another that determines the relocation of the footloose workers in Figure 1. For the empirical analysis this implies that one should not only look at the change in the size of a region or city, but also at the change of that region or city relative to the change in size of surrounding regions or cities corrected for inter-city distance. In section 4 we will deal with these issues and our "geography" extension in more detail. But first we will briefly illustrate that the strategic bombing of German cities during WW II provides indeed a large, temporary shock that makes it good candidate to look for the presence of multiple equilibria in German city-growth.

\section{The Strategic Bombing of Germany ${ }^{6}$}

During the Second World War (WWII), allied forces heavily bombed Germany. Initially these bombardments had little effect on the German war economy. The initially limited success of the air raids led to a change in bombing tactics. From March 1942 onwards, RAF bomber command launched a new bombing method. The emphasis in this new program was on area bombing, in which the centers of towns would be the main target. The central idea of this strategy was that the destruction of cities would have an enormous and destructive effect on the morale of the people living in it. The dislocation of workers would in any case disrupt industrial production even if the factories themselves were not hit. Targeted cities were not necessarily selected because they were particularly important for the war economy, but because they were visible from the air. The economic importance of cities was often not decisive in the selection of targets after the RAF initiated the changed bombing strategy, but the potential for destruction was.

On average $40 \%$ of the dwellings in the larger cities was destroyed (which is roughly comparable with the findings of Davis and Weinstein (2002) for Japan). An estimated 410.000 people lost their lives due to air raids, and at least seven million people lost their homes. As a result in 1946 the population of quite a few German cities was (in absolute terms) considerably lower than the corresponding population in 1939.

\footnotetext{
${ }^{6}$ To a large extent the information in this section is based on Brakman, Garretsen, and Schramm (2004) to which we refer for more details.
} 
Many cities in Germany were to a very significant degree destroyed by the end of WWII. The destruction was primarily caused by the bombing campaign but in contrast to Japan, also by the invasion of Germany by the allied forces. These ground battles implied additional and severe damage to cities that were in the path of the allied forces. In addition, by the end of the war the encounter between the Russian forces and the retreating German army led to an enormous inflow of refugees (Vertriebene) from former German territories and East European countries. Rough estimates indicate that between 11 and 14 million refugees had to find a new home in Germany (both in eastern and western Germany). This inflow of German refugees more than compensated for the loss of lives in Germany itself. The combined effect of the bombing campaign and the flow of refugees effected the city size distribution in Germany enormously (Brakman, Garretsen, and Schramm, 2004).

Based on the above information our conclusion is that the strategic bombing of Germany during the WW II and the consequences of the occupation of Germany by allied forces is an example of a large shock that could enable us to find evidence for multiple equilibria in the sense of Figure 2.

\section{Model Specification}

As a formal test of the WWII shock on German city growth, we employ the methodology employed by Davis and Weinstein (2002, 2004). In Davis and Weinstein (2002) the main hypothesis is whether the evidence supports the idea of unique, stable equilibrium following the WWII shock. In terms of Figure 2 they test whether it is true that the observations lie on a line with slope minus unity through the origin, that is the equilibrium depicted by $\Omega$ in Figure 2 . The possibility of other equilibria (in casu, $\Delta_{l}$ and $\Delta_{3}$ ) is not taken into account in the analysis, which means that for the case of a unique equilibrium Figure 2 reduces to one line through the origin with slope minus unity. In Davis and Weinstein (2004) the model specification allows for the possibility of multiple equilibria just as Figure 2 illustrates.

For the case of a unique equilibrium, following also Brakman, Garretsen, and Schramm (2004), the line of reasoning is as follows. The approach is basically to test whether or not the growth of city size (with city size thus as a share of total population) follows a 
random walk. The relative city size $s$ for each city $i$ at time $t$ can be represented by (in $\operatorname{logs})$ :

$$
S_{i t}=\Omega_{i}+\varepsilon_{i t}
$$

where $\Omega_{\mathrm{i}}$ is the initial equilibrium size of city $i$ and $\varepsilon_{\mathrm{it}}$ represents city-specific shocks. The persistence of a shock can be modeled as:

$$
\varepsilon_{i, t+1}=\rho \varepsilon_{i, t}+v_{i, t+1}
$$

where $v_{i t}$ is independently and identically distributed (i.i.d.) and for the parameter $\rho$ it is assumed that $0 \leq \rho \leq 1$.

By first differencing (1) and by making use of (2) we get

$$
s_{i, t+1}-s_{i, t}=(\rho-1) v_{i, t}+\left(v_{i, t+1}+\rho(\rho-1) \varepsilon_{i, t-1}\right)
$$

If $\rho=1$, all shocks are permanent and city growth follows a random walk; if $\rho \in[0,1)$, the shock will dissipate over time. From Figure 2 we know that for the initial equilibrium to be stable that there must a period $t+1$ that is long enough so as to ensure that $\rho=0$. With $\rho=0$ the shock has no persistence at all. In Figure 2 this is the case when the observations lie on the line through the origin with slope minus unity. For $0<$ $\rho<1$ there is some degree of persistence (but ultimately the impact of the shock will dissipate over time). Of course, in its multiple equilibria version with which we deal below, Figure 2 also allows for another interpretation when it would be established after estimating equation (3) that $0<\rho<1$ : that there could be multiple equilibria and that we really should test for this possibility instead of for the case of an unique equilibrium. For the simpler case of a unique equilibrium we, however, only have to test whether or not in terms of Figure 2 the observations lie on a linee through the origin with slope minus unity.

As Davis and Weinstein (2002, p.1280) note the value for the central parameter $\rho$ could be determined by employing a unit root test. The power of such a test is, however, not undisputed and the reason to use such a test is that usually the innovation $v_{i t}$ cannot be identified. In our case, as in the Japanese case of Davis and Weinstein, the innovation can be identified as long as we have valid instruments for the war shock $\left(s_{i, 1946}-s_{i, 1939}\right)$ that serves as $v_{i t}$ in the estimations for our German case below.

The basic equation to be estimated for the case of a unique equilibrium now becomes: 


$$
s_{i, 1946+t}-s_{i, 1946}=\alpha\left(s_{i, 1946}-s_{i, 1939}\right)+\beta_{0}+Z_{i}+\text { error }_{i}{ }^{7}
$$

where $\alpha=\rho-1, \beta_{0}$ is a constant and $Z_{i}$ refers to control variables one might want to include. ${ }^{8}$ If $\alpha=0$ city growth follows a random walk. If we find that $-1 \leq \alpha<0$ this is evidence that a random walk must be rejected and hence that the war shock had no effect at all $(\alpha=-1)$, or at most a temporary effect $(-1<\alpha<0)$ on relative city-growth in Germany. So, $-1 \leq \alpha<0$ is evidence for a tendency towards a mean reverting growth process. In our 2 period growth setting, $-1 \leq \alpha<0$ implies that the shock has had a permanent effect, the impact of the shock has not fully dissipated over time. To estimate equation (4) we have to choose a $t$ for the left-hand side variable $s_{i, 1946+t}-s_{i, 1946}$. We choose $t=17$ (indicating 1963) for our sample of West German cities which corresponds with the time horizon used by Davis and Weinstein (2002). Our implicit assumption here is that the period 1946-1963 should be long enough for the war shock to be fully absorbed. Also, the early 1960s mark the end of the reconstruction policies of the (west) German government. It must be emphasized that for the test of a unique equilibrium we do not want to restrict $\rho$ to be zero (and hence $\alpha=-1$ ), the data should tell us what the implied value of $\rho$ is. Only when $\rho$ is not significantly different from zero can it be concluded that the data support the case of the unique stable initial equilibrium $\Omega$ from Figure 2. When the estimation results show that $\alpha$ differs significantly from -1 (that is, $\rho$ is not 0 ), this leads one to conclude that there might be multiple equilibria.

Following Figure 2, the question is now how to change the empirical specification to allow for the possibility to actually test for multiple equilibria. To simplify matters, let's assume for the moment that we know the number of equilibria and the thresholds, like $b_{1}$ and $b_{2}$ in Figure 2, that separates the various equilibria. After we have introduced the model using these two assumptions, we will need to relax these assumptions in our empirical specification of the model with multiple equilibria. The problem is how to adapt equation (3) to take into account multiple equilibria. To answer this question, assume like in Figure 2 that there are three equilibria. The initial equilibrium is denoted (in log share) by $\Omega_{i}$, the second or low equilibrium is $\left(-\Delta_{l} \log \right)$-share units below the initial equilibrium (thus this equilibrium is located at $\Omega_{i}+\Delta_{l}$ in $\log$ space, recall Figure 2

\footnotetext{
${ }^{7}$ Note that we can include a constant because the summation over all $s$ is not equal to 1 (the share of a city is relative to the total population, and not to the sum of city sizes in our sample).

${ }^{8}$ Note that the measure of the shock (or innovation) is the growth rate between 1939 and 1946, which is correlated with the error term in the estimating equation. This indicates that we have to use instruments.
} 
from the previous section), and a third or high equilibrium at $\Omega_{i}+\Delta_{3}$. The lower and higher thresholds, are denoted by respectively $b_{1}$ and $b_{2}$ (in log shares) and let $b_{2}>b_{1}$. We then get for $s_{i, t+1}$

(5b) $s_{i, t+1}=\Omega_{i}+\varepsilon^{2}{ }_{i, t+1}$ in case $b_{1}<v_{i, t}<b_{2}$

(5c) $\quad s_{i, t+1}=\Omega_{i}+\Delta_{3}+\varepsilon_{i, t+1}^{3}$ in case $v_{i, t}>b_{2}$

Using equations (5) and subtracting (1) from (5), and also using the fact that the error terms change whenever the lower or upper threshold $b_{1}$ or $b_{2}$ is crossed, it can be shown (Davis and Weinstein (2004, pp. 21-23) that equation (3) becomes

(6a) $s_{i, t+1}-s_{i, t}=\Delta_{1}(1-\rho)+(\rho-1) v_{i, t}+\left[v_{i, t+1}+\rho(1-\rho) \varepsilon_{i, t-1}\right]$ in case $v_{i, t}<b_{1}$

(6b) $s_{i, t+1}-s_{i, t}=(\rho-1) v_{i, t}+\left[v_{i, t+1}+\rho(1-\rho) \varepsilon_{i, t-1}\right] \quad$ in case $b_{1}<v_{i, t}<b_{2}$

(6c) $s_{i, t+1}-s_{i, t}=\Delta_{3}(1-\rho)+(\rho-1) v_{i, t}+\left[v_{i, t+1}+\rho(1-\rho) \varepsilon_{i, t-1}\right]$ in case $v_{i, t}>b_{2}$

Equation (6) replaces equation (3) in our example with three equilibria. Note that equation (6b) is exactly the same as equation (3)! Note also that equations (6a)-(6c) are the same but for their constant term. As a final step and taking into account that for our case of German cities $t=1946, t+1=1963$ and also that the war shock $v_{\mathrm{i}, \mathrm{t}}=v_{\mathrm{i}, 1946}$ will be approximated (see equation 4$)$ by the wartime city growth $\left(s_{i, 1946}-s_{i, 1939}\right)$ we follow Davis and Weinstein and rewrite equation (6):

(7) $s_{i, 1963}-s_{i, 1946}=(1-\rho) \Delta_{1} I_{1}\left(b_{1}, v_{i, 1946}\right)+(1-\rho) \Delta_{3} I_{3}\left(b_{2}, v_{i, 1946}\right)+(\rho-1)\left(s_{i, 1946}-s_{i, 1939}\right)+$ $\left[v_{i, 1963}+\rho(1-\rho) \varepsilon_{i, 1933}\right]$

where $I_{1}\left(b_{1}, v_{1946}\right)$ and $I_{2}\left(b_{2}, v_{1946}\right)$ are indicator variables that equal one if $v_{i, t}<b_{1}$ or $v_{i, t}>b_{2}$ respectively.

Equation (7) is the multiple equilibrium version of equation (4). Assuming that we have valid instruments for the wartime city growth, we are now in a position to estimate equation (4) and hence to test the unique equilibrium hypothesis, but this is not the case 
for equation (7) and the multiple equilibria hypothesis. The main problem with the latter is that we have assumed that the number of equilibria is known (three in our example) and also that we know the value of the thresholds, in casu $b_{1}$ and $b_{2}$. But this has to be determined by the data, and not assumed beforehand.

Estimating a log likelihood function that is maximized for the values of the thresholds and yields coefficients for $\Delta_{1}, \Delta_{3}$ seems the appropriate methodology to estimate (7). Davis and Weinstein (2004, p. 23) argue that this is problematic given that one also needs to instrument the wartime growth, and the instrumenting equation would then include the indicator variables, but these variables are in turn a function of the instrumented shocks. To get around this econometrical problem, they impose that $\rho=0$ which means, in our case of German city growth and the WWII shock, that one assumes that whatever happens during the period of the shock (1939-1946) is precisely undone in the second period (here, 1946-1963). Or, in other words, with $\rho=0$ we assume that the war-shock has no persistence. In our view and leaving aside the econometrical problem emphasized by Davis and Weinstein, the need for the $\rho=0$ assumption already follows directly from the underlying theoretical model as summarized by Figure 2. Given that the period $t+1$ in Figure 2 is long enough for the shock from period $t$ to have dissipated, a line represents a stable equilibrium with slope minus unity because that is ultimately what a stable equilibrium implies! This also means that as opposed to the case of the unique equilibrium, when testing for multiple equilibria theory tells us to impose that $\rho=0$. If following a shock the one thing we know for sure is that the cities end up in some stable equilibrium (old or new) and that for any stable equilibrium it must be true that ultimately $\Delta S_{t}=-\Delta S_{t+1}$, which means that any other assumption than $\rho$ $=0$ is difficult to ground on the underlying model of city-growth. Or to quote Davis and Weinstein $(2004$, p. 8) at some length about the implications of the model as summarized by Figure 2:

"the 2 period growth space thus provides a very simple contrast between a model of unique equilibrium versus one of multiple equilibria. In the case of a unique equilibrium, an observation should simply lie on a line with slope minus unity through the origin. In the case of multiple equilibria, we get a sequence of lines, all with slopes minus unity, but with different intercepts. Because in this latter case these lines have slope minus unity, the intercepts are ordered and correspond to the displacement in logshare space from the initial to the new equilibrium. These elements will be central when we turn to empirical analysis" 
In our view the (very important) assumption that $\rho=0$ is thus already a consequence of the (implicit) theoretical model as summarized by Figure 2, once one assumes that the slopes of these curves are -1 . Given the assumption that in the 2-period set-up, shocks from period $t$ will have dissipated completely in $t+1$, thus with $\rho=0$ equation (7) becomes:

$$
s_{i, 1963}-s_{i, 1939}=\Delta_{1} I_{1}\left(b_{1}, v_{i, 1946}\right)+\Delta_{3} I_{3}\left(b_{2}, v_{i, 1946}\right)+\left\lfloor v_{i, 1963}+\rho(1-\rho) \varepsilon_{i, 1933}\right\rfloor
$$

Compared to equation (7), the relative city growth during the WWII period, $s_{i, 1946}-S_{i, 1939}$, has dropped out and one can now start to estimate equation (8) by selecting values for the parameters that maximize the likelihood function.

\section{Data Set and Estimation Results}

\subsection{Data set}

The data set that we used for the present paper is basically the same one as in Brakman, Garretsen and Schramm (2004); we therefore refer to the latter for more details on the bombing and destruction of German cities during WWII. The sample consists of cities in the territory of present-day Germany that either had a population of more than 50.000 people in 1939 or that were in any point of time in the post-WWII period a so called Großstadt, a city with more than 100.000 inhabitants. This yields a sample of 103 cities in total, consisting of 81 West German and 22 East German cities. Based on our previous work we decided to restrict the analysis to the sub-sample of West-German cities. There are a number of reasons for doing this. First, the sub-sample for EastGerman cities is rather small and data on war destruction are not as readily available for the GDR period. Secondly, and more importantly, in the post-WWII period EastGerman cities were part of the communist GDR with its central planning in which economic agents were definitely not free to choose their location. This is very much at odds with the basic theory; see section 2, which underlies our empirical specification.

To analyze post WWII-city growth, we need cross-section data on the WWII-shock and time series data on city population. With respect to the former, Kästner (1949) provides West German cross-section data about the loss of housing stock in 1945 relative to the housing stock in 1939 , and rubble in $\mathrm{m}^{3}$ per capita in 1945 . Data on the number of war 
casualties are only available for a sub-set of our cities and are, as opposed to the case of Japan, probably not a good indicator of the war-shock to start with. ${ }^{9}$ This leaves us with two variables that measure the degree of destruction.

Time series data of city population are from the various issues of the Statistical Yearbooks, and for 1946 also from the Volks- und Berufszählung vom 29. Oktober 1946 in den vier Besatzungszonen und Groß-Berlin. As we will run regressions on the relative size of cities before and after the WWII (city size relative to the total population), we also need statistics on the national population. This is not as easy as it might seem, because the German border did change after WW II. There are pre-WW II time series of population for the part of Germany that became the Federal Republic of Germany (FRG), that is West Germany, in 1949 (Federal Statistical Office). To allow for the impact of geography we included the geodesic distance between cities, see below. Finally, as an alternative to city population we use data on so called Gewerbesteuer (corporate taxes) on the city level to measure city growth. These tax data were taken from Statistical Yearbooks and are an indicator of the degree of economic activity.

\subsection{The case of a unique equilibrium and the relevance of geography}

As we explained in the previous section, for the case of a unique equilibrium we estimate equation (4) where we have to instrument the relative city-growth during WWII: $s_{i, 1939-S_{i, 1946}}$ The city-specific instruments are the destruction of the housing stock between 1939-1945, and the rubble per capita per $\mathrm{m}^{3}$ in 1945 . In addition, we introduce the role of geography in two ways:

1. The relative city growth from 1939-1946 is not only instrumented by its own destruction but also by a sum of the distance weighted housing destruction and rubble variables of all other cities. In a very simple way this captures the idea that the "geography" of bombing may matter, in the sense that the city growth of

\footnotetext{
${ }^{9}$ For the German case it is in our view not straightforward to include the number of casualties per city as a variable measuring the degree of destruction. Systematic data on casualties are lacking and if they were available they include prisoners of war (PoWs), foreign workers (Fremdarbeiter), and refugees and are therefore not a good indicator of the destruction of a city. For a sub-set of cities, based on Friedrich (2002), we have city data on casualties and from these data we know that PoWs, refugees and foreigners often contributed more than proportionally to a city's death toll (they were often denied shelter during bombardments). The distribution of these "temporary" inhabitants of a city was often not linked to the size of the city. This means that, as opposed to the case of Japan as analyzed by Davis and Weinstein $(2002,2004)$, the number of casualties is probably not a good indicator of city destruction as the change in the housing stock.
} 
city $i$ during WWII is also determined by the (exogenous) degree of destruction of other cities corrected for distance, see also Figure 1. Hence, as opposed to Davis and Weinstein (2004), the relative city growth of a city is thereby no longer only a function of city-specific variables, that is to say it is no longer independent from the fate of other cities. ${ }^{10}$ Linking cities in this manner is not a problem since the war shock is assumed to be exogenous. We label this extension $\underline{G E O-I}$

2. In equation (4) we add the distance between city $i$ to the one of the three westGerman economic centers (Hamburg, Köln, München) as a control variable, so

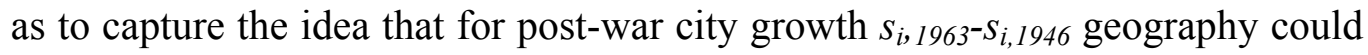
matter as well. In line with for instance a simple market potential function or more elaborate new economic geography models, the distance from economic centers is thought to be able to affect a city's growth rate. We label this extension $\underline{G E O-I I}$

Without geography, the estimation of (4) using our 2 instruments should yield the same results as in Brakman, Garretsen, and Schramm (2004) for the case of WestGerman cities. This is indeed the case. ${ }^{11}$ Table 1 presents the estimation results for the model specification with a unique equilibrium. The upper panel gives the $1^{\text {st }}$ stage estimation results and the lower panel the $2^{\text {nd }}$ stage results. The various columns differ to the extent that the geography extension GEO-I and GEO-II were used.

\footnotetext{
${ }^{10}$ Without geography WWII city growth is instrumented in a ${ }^{\text {st }}$ stage regression as follows: $s_{i, 1946} S_{i, 1939}=\mu+\varphi_{1} \ln (\text { housing stock })_{i}+\varphi_{2} \ln \left(\right.$ Rubble $_{i}+\psi Z_{i}+\varepsilon_{i}$, where $\mathrm{Z}$ are the exogenous variables, if any, in equation (4) With geography we get: $s_{i, 1946}-S_{i, 1939}=\mu+\varphi_{1} \ln \left(\sum D_{i j}^{\delta} \text { housing stock }\right)_{i}+\varphi_{2} \ln \left(\sum D_{i j}^{\delta} \text { Rubble }\right)_{i}+\psi Z_{i}+\varepsilon_{i}$, where $\mathrm{D}_{\mathrm{ij}}$ is the distance between city $\mathrm{i}$ and city $\mathrm{j}$, and $\delta$ is the distance decay parameter that needs to be estimated. Davis and Weinstein (2004, p. 9) acknowledge that the fact that the relative growth of a city is independent of the evolution of other city sizes as a limitation of their approach.

${ }^{11}$ With one caveat: for the actual estimations growth rates are constructed using $\left(x_{t}-x_{t-i}\right) / x_{t-i}$ instead of the approximation $\ln \left(x_{t}\right)-\ln \left(x_{t-i}\right)$ that we, following Davis and Weinstein (2002), used in our previous paper. In their discussion of these papers, Head and Mayer (2004) rightly stress that this approximation is only valid for small changes and large changes cannot be ruled out.
} 
Table 1a, $1^{\text {st }}$ stage regression results

\begin{tabular}{|l|l|l|l|l|}
\hline$\Delta \boldsymbol{s}_{\boldsymbol{i}, 1946-1939}$ & No geography & GEO-I & GEO-II & GEO-I +GEO-II \\
\hline Constant & $0.203^{* * *}$ & $0.210^{* * *}$ & $0.138^{* *}$ & $0.164^{* *}$ \\
\hline Dist. Decay, $\delta$ & - & $-2.215^{* * *}$ & - & $-1.918^{* * *}$ \\
\hline In(housing) & $-0.055^{* *}$ & $-0.051^{*}$ & $-0.079^{* * *}$ & $-0.078^{* * *}$ \\
\hline ln(rubble/cap.) & $-0.096^{* * *}$ & $-0.104^{* * *}$ & $-0.086^{* * *}$ & $-0.098^{* * *}$ \\
\hline Dummy $_{\text {Berlin }}$ & - & - & -0.112 & -0.119 \\
\hline Distance $_{\text {München }}$ & - & - & $0.0003^{* * *}$ & $0.0003 * * *$ \\
\hline Adj. $\mathrm{R}^{2}$ & 0.629 & 0.629 & 0.693 & 0.699 \\
\hline
\end{tabular}

Where, "-“ indicates that the variable is not relevant for that model variant, ***=significant $1 \%$ level, $* *=$ significant $5 \%$ level, $*=$ significant $10 \%$ Level

Table $1 b, 2^{\text {nd }}$ stage regression results

\begin{tabular}{|l|l|l|l|l|}
\hline$\Delta \mathbf{s}_{\mathbf{i}, 1963-1946}$ & No Geography & GEO-I & GEO-II & Geo-I +GEO-II \\
\hline Constant & $0.099 * * *$ & $0.101^{* * *}$ & $0.210^{* * *}$ & $0.212^{* * *}$ \\
\hline $\begin{array}{l}s_{i, 1946-S_{i, 1939}}(\alpha=\rho-1) \\
\text { Dummy }_{\text {Berlin }}\end{array}$ & $-0.550^{* * *}$ & $-0.538^{* * *}$ & $-0.627 * * *$ & $-0.617 * * *$ \\
\hline Distance $_{\text {München }}$ & - & & & \\
\hline SER & 0.167 & - & $-0.393^{* *}$ & $-0.392^{* *}$ \\
\hline
\end{tabular}

See, Table 1a for explanation.

In addition to the variables introduce above, a dummy for Berlin has been added in specifications where geography matters. This amounts to excluding Berlin from the data set as (the western part of) this city in the period under consideration was isolated from the rest of West Germany. München is included as our economic centre. The estimations suggest that cities closer to München grow faster. ${ }^{12}$ We also looked for a

\footnotetext{
${ }^{12}$ When we took Köln as the economic centre, the resulting coefficient was not significant, and when we opted for Hamburg, the distance coefficient became $+0.0003^{* * *}$ which supports the idea that cities in the South grew faster.
} 
possible effect of the former FRG-GDR border in the sense that we included the distance between a West-German (FRG) city and the border of East Germany (the GDR). The results were, however, insignificant once the Berlin dummy was added to our set of explanatory variables in equation (4). ${ }^{13}$

As to the relevance of geography in the $1^{\text {st }}$ stage regression (the war shock), see Table 1a, we find that the distance decay parameter is significant and around -2 . The latter implies that the impact of the war-shock of another city on the city growth of city $i$ quickly becomes quite small when the distance between city $i$ and the other city, $D_{i j}$, increases. For city $i$, it is above all the own destruction that matters and both instruments (housing and rubble) are highly significant. All in all the conclusion must be that the geography variables are significant but that they do not change the main result as to the coefficient for the instrumented wartime city growth $s_{i, 1946}-S_{i, 1939}$. This coefficient, the $\alpha$-coefficient in equation (4), is our main interest here (see Table 1b). Recall from section 4 that $\alpha=\rho-1$ and we thus find that the estimated coefficient is clearly significantly different from -1 which would have been an indication of complete mean reversion in 1963. We find mean reversion in the sense that the average West-German city recaptured about $50 \%$ of the war shock (positive or negative in relative terms) by 1963. So there is a tendency to return to the pre-war growth path but this tendency, as opposed to the findings of Davis and Weinstein for Japan, is far from complete. Adding government reconstruction expenses or pre-war city growth as city-specific control variables did not change our results.

Table $1 \mathrm{~b}$ shows that adding geography, and hence allowing for spatial interdependencies between cities, does not change the conclusions from Brakman, Garretsen, Schramm (2004) despite the fact that the geography variables are significant. The question is of course whether this conclusion also holds when we add geography to the multiple equilibria framework. Before we address this question, a final remark on how our findings in table 1 relate to the corresponding estimation results by Davis and Weinstein. They find for Japan when they use city-population as their dependent variable that the $\alpha$-coefficient is not statistically different from -1 , which thus means

\footnotetext{
${ }^{13}$ Redding and Sturm (2005) find, however, evidence that supports the relevance of the FRG-GDR split for border regions in West Germany (FRG). Their approach differs in a number of important ways from our analysis so it is difficult to compare these findings.
} 
that the presence of a unique equilibrium is borne out by the data as valid for the case of Japan. It is indeed the case for Japan that the observations in the $S_{t}, \mathrm{~S}_{\mathrm{t}+1}$ space of Figure 2 can be arranged on a line through the origin with slope minus unity. The latter is thus not the case for our sample of West German cities. Given this difference one may argue that it is more interesting for the German case to start to look for multiple equilibria then it is for the case of Japan. Davis and Weinstein (2004, p. 10) note that a finding (like in our Table 1) that $\alpha$ is significantly different from -1 is sufficient to establish that there somehow must be multiple equilibria.

\subsection{Multiple equilibria and the relevance of geography}

In section 4 we arrived at equation (8) as the specification to be used to test for the possibility of multiple equilibria. In line with the model underlying Figure 2 we also assume that $\rho=0$ (or in terms of Table $1, \alpha=-1$ ). This assumption follows the theoretical set-up in Davis and Weinstein and simply means that the war-shock (the $1^{\text {st }}$ period, here 1939-1946) has completely and exactly been reversed in the subsequent period (here, 1946-1963). Before we can present our estimation results for the multiple equilibria cum geography case, we will first briefly explain the estimation strategy employed by Davis and Weinstein to estimate their equivalent of equation (8) for Japan. Using the model underlying Figure 2, we can re-write equation (8):

(9) $s_{i, 1963}-s_{i, 1939}=\delta_{2}+\delta_{1} I_{1}\left(b_{1}, v_{i, 1946}\right)+\delta_{3} I_{3}\left(b_{2}, v_{i, 1946}\right)+\gamma Z_{i}+\mu_{i}$

Compared to equation (8) a constant term has been added to allow for a non-zero mean error term, $Z_{\mathrm{i}}$ stands for control variables like the government reconstruction expenses or the pre-war growth rate that one might want to include, $\delta$ is to be estimated, and $\mu$ is the error term. The constant represents the equilibrium in Figure 2 on the line that cuts through the origin with slope minus unity. The fact that $\delta_{2}$ (the constant term) represent the second equilibrium from the left is nothing but a normalization. In line with the theoretical set-up larger negative (positive) shocks should push a city to smaller (higher) equilibria. So when interpreting the estimation results the following restriction on the estimated parameters should be kept in mind that is the ordering of the intercepts should be (assuming there are most 3 equilibria): ${ }^{14}$

$$
\delta_{1}+\delta_{2}<\delta_{2}<\delta_{2}+\delta_{3} \text { which is identical to } \delta_{1}<0<\delta_{3} \text {. }
$$

\footnotetext{
${ }^{14}$ The first equilibrium intercept is: constant $+\delta_{1}$; the second equilibrium: constant $\left(=\delta_{2}\right)$; the third equilibrium: $\delta_{2}+\delta_{3}$ etc.
} 
A second requirement from the theory as summarized by Figure 2, is that the thresholds $b_{1}$ and $b_{2}$ lie between the equilibria. This means that we get the following final intercept ordering condition:

$$
\delta_{1}<b_{1}<0<b_{2}<\delta_{3}
$$

Since we do not know the thresholds or the number of equilibria we have to let the data pick the corresponding parameter values that maximize the likelihood function using a grid-search technique. Using the same strategy as Davis and Weinstein (2004, pp. 2526) we estimate these parameters (notably $\delta_{1}$ and $\delta_{3}$ ) for the three equilibria case as follows. ${ }^{15}$ First the relative population growth of each city between 1939 and 1946 is regressed on our preferred destruction variables (housing stock destruction in 1945, and rubble per capita per $\mathrm{m}^{3}$ in 1945). We then multiplied for each city the housing stock destruction and the rubble variable by their respective estimated coefficients so as to arrive at city specific measurement of the war shock. Second, we used these shock data to group the data as follows (where we take the case of three equilibria as an example): the grouping of the war shock data allows us to derive the thresholds $b_{1}$ and $b_{2}$. We divide the data into 3 groups and we assume initially that the thresholds occur at any percentile that is a multiple of 5 (other multiples are also possible, but would suggest a level of detail that is not supported by the data). So thresholds occur at $(5 ; 10),(5 ; 15), \ldots$, then $(10 ; 15),(10 ; 20) \ldots$, etc until all combinations have been tried. For each threshold combination we calculate the maximum likelihood parameters and then choose those threshold and parameter values that give us the maximum values of the likelihood function. ${ }^{16}$. Doing this for all possible combinations of $5 \%$ quantiles and selecting the one that maximizes the likelihood function gives the estimated output as shown in Table 2.

\footnotetext{
${ }^{15}$ We also checked if we could find evidence of more than 3 equilibria but this was never these case so we restrict ourselves here to the case of (at most) 3 equilibrium.

${ }^{16}$ For 2 equilibria a similar grid search procedure based on $5^{\text {th }}$ percentiles on the war shock data was followed but with 2 equilibria there is only 1 threshold to take into account. For the case of a unique equilibrium one has 2 options. The first one is to go about as we did in Table 1 (were $\rho$ was not constrained to be zero), the second option is assume that $\rho$ and thus obtain a likelihood function that can be estimated.
} 
In addition, we incorporate the role of geography in a similar vein as for the case of a unique equilibrium reported in Table 1. In constructing the war shock data that is the basis for the grid search, we ran regressions in which only the own city destruction entered (the No Geo columns in Table 2) and regressions in which we took geography into account by letting the destruction of other cities (weighted by distance) also be a determinant of the war shock data (the Geo columns in Table 2). Finally, given the significance of the geography variables in the $2^{\text {nd }}$ stage regression as shown in Table $1 \mathrm{~b}$ we included the Berlin dummy and the distance to München in our set of control variables when estimating equation (9).

Table 2. Estimation results for multiple equilibria and the role of geography

\begin{tabular}{|c|c|c|c|c|}
\hline$\Delta s_{i, 1963-1939}$ & $\begin{array}{l}\text { No Geo, } 2 \\
\text { equil. }\end{array}$ & $\begin{array}{l}\text { No Geo, } 3 \\
\text { equil. }\end{array}$ & Geo, 2 equil. & Geo, 3 equil. \\
\hline Constant $\left(=\delta_{2}\right)$ & $0.219 * * *$ & -0.055 & $0.284 * * *$ & $0.458 * * *$ \\
\hline Dummy $y_{\text {Berlin }}$ & $-0.389 * * *$ & $-0.419 * * *$ & $-0.419 * * *$ & $-0.413 * * *$ \\
\hline Distance $_{\text {München }}$ & $-0.0003 * * *$ & $-0.0002 * *$ & $-0.0002 * *$ & $-0.0003 * * *$ \\
\hline$\delta_{1}$ & $-0.141^{* * *}$ & $0.134^{* *}$ & $-0.193^{* * *}$ & $-0.341^{* * *}$ \\
\hline $\mathrm{b}_{1}$ threshold & -0.191 & -0.234 & -0.004 & -0.004 \\
\hline$\delta_{3}$ & - & $0.249^{* * *}$ & - & $-0.220^{* * * *}$ \\
\hline $\mathrm{b}_{2}$ threshold & - & -0.191 & - & 0.017 \\
\hline LogLik. & 38.389 & 41.074 & 38.766 & 41.710 \\
\hline AIC, Akaike & -0.893 & -0.937 & -0.903 & -0.954 \\
\hline SBC, Schwartz & -0.771 & -0.785 & -0.781 & -0.801 \\
\hline $\begin{array}{l}\text { Intercept Order. } \\
\text { Criteria (eq.10) } \\
2 \text { equilibria: } \\
\delta_{1}<\mathrm{b}_{1}<0 \\
3 \text { equilibria: } \\
\delta_{1}<\mathrm{b}_{1}<0<\mathrm{b}_{2}<\delta_{3}\end{array}$ & Fail & Fail & Accept & Fail \\
\hline
\end{tabular}

Where ${ }^{*},{ }^{* *}{ }^{* * *}$ denotes significance at the $10 \%, 5 \%$, and $1 \%$ level respectively.

\begin{tabular}{|c|c|c|}
\hline LR-stat (\# equilibria) & No Geo & Geo \\
\hline 1 vs 2 & 15.144 & 15.898 \\
\hline 2 vs 3 & $5.370^{* *}$ & $5.888^{* *}$ \\
\hline
\end{tabular}

Test statistic is distributed as $\chi(1)$. And ${ }^{* *}$ denotes significance at the $5 \%$ level. 
The Likelihood Ratio (LR) test rejects 1 equilibrium against 2 equilibria for all specifications. When 2 equilibria are tested against 3 equilibria, this is accepted at the $5 \%$ level. ${ }^{17}$

Table 2 does not show the results for the case of 1 equilibrium since we already know from Table 1 what the conclusions are. ${ }^{18}$ For the case of 2 equilibria $\left(1^{\text {st }}\right.$ and $3^{\text {rd }}$ column) we find that $\delta_{1}<0$ which is what theory tells us to expect. Larger negative shocks push cities to smaller equilibria. But the ordering criterion, which also takes the threshold restrictions into account $\left(\delta_{1}<b_{1}<0\right.$, see last row of the Table), is only met when we allow geography to play a role. So there is evidence in favour of 2 equilibria. Furthermore the LR-test, see bottom of Table 2, indicates that the null hypothesis of a unique equilibrium versus the alternative of 2 equilibria is always rejected ( $p$-value: 0.00). Given the fact that the estimations in Table 2 are based on the assumption of $\rho=0$ $(\alpha=-1)$ evidence in favour of multiple equilibria is less of a surprise if one takes into account that we found $\alpha$ to be around -0.6 in Table $1 \mathrm{~b}$ for the case of a unique equilibrium. This also helps to explain why Davis and Weinstein find no evidence in favour of multiple equilibria (given that they already established that $\alpha$ is (almost) -1 in their equivalent of estimating equation (4) for city population in Japan).

When one allows for 3 equilibria it is true both in the geography and the non-geography case $\left(4^{\text {th }}\right.$ and $2^{\text {nd }}$ column respectively) that the $\delta$-coefficients are significant but that the restriction, $\delta_{1}<0<\delta_{3}$, only holds for the non-geography case. For this case the threshold criterion is not met (last row of Table 2). In addition, the LR-test indicates that we cannot reject the null of 2 equilibria versus the alternative of 3 equilibria at the $1 \%$ level ( $p$-value:0.02). ${ }^{19}$ So there is no firm evidence to support the model with 3 equilibria.

\footnotetext{
${ }^{17}$ A different approach to the same problem (testing for a threshold) can be found in Hansen (1996. 2000). Using Hansen (1996) we can test for the presence of 1 threshold in the war shock data for our sample of West German cities. This requires that all parameters are allowed to be different for the two subgroups, this is only possible for our specification when we do not include the Berlin-dummy or the distance to Munich variable. We then find evidence in favour 2 equilibria (instead of 1 equilibrium).

${ }^{18}$ When we did estimate equation (9) for the case of 1 equilibrium we found, not very surprisingly, that coefficients for the 3 variables (constant, Berlin-dummy, distance to München) are somewhat different to those reported in Table 1, the reason being that we now impose that $\rho=0(\alpha=-1)$ and the estimation results shown in Table 1 indicate that $\rho$ is not zero $(\alpha=-0.6)$ for Germany. When we estimated equation without the Berlin dummy and the distance to München, the evidence in favour of the "geo-2 equilibrium" model is less clear-cut.

${ }^{19}$ Results for more than 3 equilibria did not improve matters and never met the ordering criteria.
} 
Our overall conclusions are twofold. First, there is evidence in favour of multiple equilibria for the case of German city growth and the WWII shock. If we take the ordering restrictions that follow from Figure 2 into consideration, we conclude that the German case is best described by 2 equilibria and also that this 2 equilibria specification is to be preferred to the case of a unique equilibrium. ${ }^{20}$ This is in contrast with the case of Japan as analysed by Davis and Weinstein. Second, the preference for the 2 equilibria specification crucially depends on the inclusion of geography in the construction of the city-specific war shock variable. Without geography, the evidence for multiple equilibria is much weaker because the ordering criteria are not met. So, geography really matters. This shows that it can make a difference whether or not spatial interdependencies between cities are allowed to play a role. Our operationalisation of geography is very simple, and can no doubt be improved upon, but our results suggest that its incorporation may make a crucial difference. A more elaborate analysis of geography into the multiple equilibrium framework of this paper would be an interesting topic for further research.

\subsection{Further discussion}

Finally, a few remarks as to the underlying model and the potential for further research. First, from section 2 we know that the new economic geography model by Krugman (1991) is the benchmark for the estimations. The ordering criteria that follow from this model are clearly very important for our conclusions with respect to the relevance of multiple equilibria (and this also holds for the conclusions in Davis and Weinstein (2004) about Japan). ${ }^{21}$ Without these criteria, conclusions as to the preferred model are different (see Akaike (AIC) and Schwartz (SBC) information criteria in Table 2). Further research should tell us whether and how restrictions like those given by equation (10) are consistent with other NEG models. To illustrate this, consider the following example. Puga (1999) develops a model in which the graph of long run equilibria with a region's share of the footloose production as a function of transportation costs, takes the form of a bell-shaped curve. This implies that different

\footnotetext{
${ }^{20}$ The maximum likelihood for the 2 equilibrium case with geography was achieved for an $85-15 \%$ split of the war shock data. This means, with a threshold of $b_{1}=-0.004$ (see Table 2), that the following 12 relatively less "war struck" cities remained in the initial equilibrium $\Omega$ of Figure 2: Flensburg, Neumünster, Lübeck, Herne, Recklinghausen, Leverkusen, B-Gladbach, Göttingen, Heidelberg, Erlangen, Regensburg, and Ingolstadt.

${ }^{21}$ See for instance Davis and Weinstein (2004, p. 33) where without the ordering criteria one would pick the model with 2 equilibria as the preferred model.
} 
long run equilibria may be characterized by the same relative city-size (but for different values of the transportation costs). So the question becomes how to construct ordering criteria when a particular $S_{i}$ can be associated with multiple equilibria.

Second, as we discussed in section 4 , the constraint that $\rho=0$ is imposed by Davis and Weinstein (2004) for econometrical reasons too (besides the justification for this assumption provided by Figure 2). We also estimated equation (9) when $\rho$ is not constrained to any specific value, and where we instrumented the war shock in a similar way as in Table 1 . Here too, we found that the inclusion of geography makes a real difference. The reason to stick to the $\rho=0$ assumption in Table 2 is that this assumption is in line with the theoretical model on which Figure 2 is based (any other slope than minus unity in Figure 2 is difficult to rationalize in our view to start with). ${ }^{22}$

Third, one of the innovations of Davis and Weinstein (2004) is that they not only test their equivalent of equations (4) and (9) with city-population as the city-growth variable but they are (quite uniquely) able to do similar estimations with total manufacturing activity and even sector data on manufacturing activity as indicators of city growth. This is interesting because the location behaviour of citizens and firms following a shock like the WWII destruction might be quite different. For these alternative city growth measures Davis and Weinstein do, however, also not find evidence of multiple equilibria. Unfortunately, city specific data on economic activity for the period under consideration are not available for German cities. The best we could come up with based on our main data source, the Statistical Yearbook, was the use of city data on Gewerbesteuer (corporate taxes). Correcting for differences in tax rates between cities and over time, we took changes in a city's corporate tax income (relative to the corresponding corporate tax income for West Germany as a whole), as an indicator of the relative change of the degree of economic activity for each city in our sample. Using the relative change of cities' corporate tax receipts, we estimated the same specifications as to those underlying Tables 1 and 2 for relative population growth. The

\footnotetext{
${ }^{22}$ When we estimate equation (9) for the "unconstrained" $\rho$, the wartime city growth enters equation (9) (compare equations (8) and (9)). We then first regress wartime growth on the housing stock and rubble variable and next proceed in a similar fashion as with the estimations for Table 2: we use the fitted values of this regression to construct the war shock variable for each city and based on the data for this variable we perform our grid search as outlined in the main text. When we allow cities to have different intercepts (but the same rate of mean reversion, so the war shock coefficient is the same for all cities), we again find that the results vary whether or not we do geography into account. The war shock coefficient is about -0.5 (in line with Table 1).
} 
results are in line with those reported in Tables 1 and 2 (see Appendix). When we excluded the outlier Hamburg from our sample, the estimation of equation (4) yields an $\alpha$-coefficient of -0.552 in the GEOI+II case (with rubble per capita but not the housing stock being significant in the $1^{\text {st }}$ stage). Estimating equation (9) with the relative change in cities' Gewerbesteuer as the dependent variable, also shows that the model with multiple equilibria is to be preferred to the model with an unique equilibrium: we now even find evidence for the case of 3 equilibria especially when geography is added (the ordering criteria are met too in this case as the Appendix illustrates). These results suggest that it may be worthwhile to look in more detail at other (and preferred) indicators of economic activity on the city level. ${ }^{23}$

Fourth, and finally, for Germany the $20^{\text {th }}$ century provides potentially interesting other shocks to assess the impact of large, temporary shock on city-growth. Apart from WWII, the split of Germany in the FRG and the GDR after WWI and the subsequent reunification of Germany in 1989 come to mind as well as the impact of WWI and the turmoil between 1918 and 1939. In order to analyse these shocks too, the present framework will, however, not do because of the fact that these shocks are not cityspecific (like the FRG GDR split in 1949). Different techniques like (panel) unit root tests are called for analyse the multitude of shocks that hit German cities in the past century. This is the topic we hope to take up next.

\section{Conclusions}

Many modern trade and growth models are characterized by multiple equilibria, but it is difficult to test for the presence of multiple equilibria. Davis and Weinstein (2002) and Brakman, Garretsen and Schramm (2004) study the effects of a large exogenous shock (WWII) on city growth for the case of Japan and Germany respectively. They both find evidence that the WWII shock tended to undo itself over time, although only partially for the case of Germany. This would suggest that city growth is not characterized by multiple equilibria. Based on the methodology developed by Davis and Weinstein (2004) for the case of Japanese cities and WWII, we test explicitly for multiple equilibria for West German cities in the present paper. In doing so, and in addition to the Davis and Weinstein framework, we look at the spatial interdependencies between

\footnotetext{
${ }^{23}$ One way to go about (see Redding and Sturm, 2005) might be to try to make use of Census-data that provide city-specific information on the production structure and employment.
} 
cities. The main findings are twofold. First, multiple equilibria seem to be present in the evolution of German city size distribution. We find evidence of a model with 2 stable equilibria. Second, the explicit inclusion of geography matters. Evidence for multiple equilibria is weaker when spatial interdependencies are not taken into account.

Appendix: Estimations results with Corporate Tax Income (Gewerbesteuer), $\Delta t_{i, t}$

I) Testing for a unique equilibrium (estimation of equation (4))

Table A1, $1^{\text {st }}$ stage regression results

\begin{tabular}{|l|l|l|l|l|}
\hline $\boldsymbol{\Delta t}_{\boldsymbol{i}, 1946-1939}$ & No geography & GEO-I & GEO-II & $\begin{array}{l}\text { GEO-I +GEO- } \\
\text { II }\end{array}$ \\
\hline Constant & $0.427^{* * *}$ & $0.432^{* * *}$ & $0.281^{* *}$ & $0.324^{*}$ \\
\hline Dist. Decay, $\delta$ & - & -2.993 & - & $-1.908^{* *}$ \\
\hline In(rubble/cap.) & $-0.187^{* * *}$ & $-0.188^{* * *}$ & $-0.186^{* * *}$ & $-0.204^{* * *}$ \\
\hline Dummy $_{\text {Berlin }}$ & - & - & $-0.858^{* *}$ & $-0.869^{* *}$ \\
\hline Distance $_{\text {München }}$ & - & - & 0.0004 & 0.0004 \\
\hline Adj. $\mathrm{R}^{2}$ & 0.229 & 0.219 & 0.276 & 0.268 \\
\hline
\end{tabular}

Where, "-“ indicates that the variable is not relevant for that model variant, ***=significant $1 \%$ level, $* *=$ significant $5 \%$ level, *=significant $10 \%$ level; Hamburg is excluded from the sample

Table A2, $2^{\text {nd }}$ stage regression results

\begin{tabular}{|l|l|l|l|l|}
\hline$\Delta \mathbf{t}_{\mathbf{i}, 1963-1946}$ & No Geography & GEO-I & GEO-II & Geo-I +GEO-II \\
\hline Constant & -0.060 & -0.056 & 0.150 & 0.0 .143 \\
\hline $\begin{array}{l}t_{i, 1946}-t_{i, 1939} \\
(\alpha=\rho-1)\end{array}$ & $-0.360^{*}$ & -0.427 & $-0.383^{*}$ & $-0.522^{* *}$ \\
\hline Dummy $_{\text {Berlin }}$ & - & - & & \\
\hline Distance $_{\text {München }}$ & - & - & 0.099 & -0.034 \\
\hline
\end{tabular}

See Table A1 for explanation. 
II) Testing for multiple equilibria (estimation of equation (9))

Table A3 Estimation results for multiple equilibria with corporate tax income

\begin{tabular}{|l|l|l|l|l|}
\hline$\Delta \boldsymbol{t}_{i, 1963-1939}$ & $\begin{array}{l}\text { No Geo, } 2 \\
\text { equil. }\end{array}$ & $\begin{array}{l}\text { No Geo, } 3 \\
\text { equil. }\end{array}$ & Geo, 2 equil. & Geo, 3 equil. \\
\hline Constant $\left(=\delta_{2}\right)$ & $0.323^{* *}$ & 0.128 & $0.322^{* * *}$ & 0.154 \\
\hline Dummy ${ }_{\text {Berlin }}$ & -0.403 & 0.136 & -0.400 & -0.154 \\
\hline Distance ${ }_{\text {München }}$ & -0.0004 & -0.0005 & -0.0004 & $-0.0006^{*}$ \\
\hline$\delta_{1}$ & $-0.263^{* *}$ & $0.546^{*}$ & $-0.286^{* * *}$ & $-0.561^{*}$ \\
\hline $\mathrm{b}_{1}$ threshold & -0.139 & -0.232 & -0.149 & -0.242 \\
\hline$\delta_{3}$ & - & $0.245^{* *}$ & - & $-0.285^{* *}$ \\
\hline $\mathrm{b}_{2}$ threshold & - & -0.139 & - & 0.183 \\
\hline \begin{tabular}{l} 
LogLik. \\
\hline AIC, Akaike
\end{tabular} & -38.233 & -36.514 & -37.593 & -35.899 \\
\hline $\begin{array}{l}\text { Intercept Order. } \\
\text { Criteria (eq.10) } \\
2 \text { equilibria: } \\
\delta_{1}<\mathrm{b}_{1}<0 \\
3 \text { equilibria: } \\
\delta_{1}<\mathrm{b}_{1}<0<\mathrm{b}_{2}<\delta_{3}\end{array}$ & Fail & -1.107 & -1.109 & 1.09 \\
\hline
\end{tabular}

Where ${ }^{*},{ }^{* * * *}$ denotes significance at the $10 \%, 5 \%$, and $1 \%$ level respectively. 


\section{References}

Brakman, S., H. Garretsen, and Ch. van Marrewijk. 2001. An introduction to Geographical Economics: Trade, Location and Growth, Cambridge University Press, Cambridge.

Brakman, S. , H.Garretsen, and M.Schramm (2004), The Strategic Bombing of German Cities during WWII and its impact on City Growth, Journal of Economic Geography, Vol.4, pp.201-218.

Davis, D. and D.Weinstein (2002), Bones, Bombs, and Break points: the Geography of Economic Activity, American Economic Review, Vol.92, pp. 1269-1289.

Davis, D. and D.Weinstein (2004), A Search for Multiple Equilibria in Urban Industrial Structure, NBER Working Paper, No. 10252, Cambridge, Mass.

Fujita, M., P. Krugman and A.J. Venables, 1999, The Spatial Economy, MIT Press.

Friedrich, J, 2002, Der Brand, Deutschland im Bombenkrieg 19401-1945, München. Gabaix, X. and Y. Ioannides (2004), The Evolution of City Size Distribution, in: J.V.Henderson and J-F Thisse, Handbook of Regional and Urban Economics: Cities and Geography, Vol.4, Elsevier North-Holland, Amsterdam.

Hansen, B (1996), Inference when a Nuisance Parameter is not Identified under the Null Hypothesis, Econometrica, vol. 64(2), pp. 413-430

Hansen, B. (2000), Sample Splitting and Threshold Regression, Econometrica, vol. 69(2), pp. 575-603.

Head, K. and T. Mayer (2004), The Empirics of Agglomeration and Trade, in: J.V.Henderson and J-F Thisse, Handbook of Regional and Urban Economics: Cities and Geography, Vol.4, Elsevier North-Holland, Amsterdam.

Kästner, F. (1949), Kriegsschäden (Trümmermengen, Wohnungsverluste, Grundsteuerausfall und Vermögensteuerausfall), Statistisches Jahrbuch Deutscher Gemeinden, vol. 37, pp. 361-391.

Krugman, P. 1991. Increasing Returns and Economic Geography, Journal of Political Economy, nr. 3, 483-499.

Puga, Diego. 1999. The rise and fall of regional inequalities, European Economic Review, Vol. 43, 303-334.

Redding, S. and D. Sturm, 2005, The Costs of Remoteness: Evidence from German Division and Reunification, CEPR Discussion Paper, no. 5015, London.

Redding, S., D.M.Sturm, and N. Wolf (2005), Multiple Equilibria in Industrial Location: Evidence From German Airports, Mimeo, London. 


\section{CESifo Working Paper Series}

(for full list see www.cesifo-group.de)

1489 Johannes Becker and Clemens Fuest, Does Germany Collect Revenue from Taxing Capital Income?, June 2005

1490 Axel Dreher and Panu Poutvaara, Student Flows and Migration: An Empirical Analysis, June 2005

1491 Bernd Huber and Marco Runkel, Interregional Redistribution and Budget Institutions under Asymmetric Information, June 2005

1492 Guido Tabellini, Culture and Institutions: Economic Development in the Regions of Europe, July 2005

1493 Kurt R. Brekke and Michael Kuhn, Direct to Consumer Advertising in Pharmaceutical Markets, July 2005

1494 Martín Gonzalez-Eiras and Dirk Niepelt, Sustaining Social Security, July 2005

1495 Alfons J. Weichenrieder, (Why) Do we need Corporate Taxation?, July 2005

1496 Paolo M. Panteghini, S-Based Taxation under Default Risk, July 2005

1497 Panos Hatzipanayotou and Michael S. Michael, Migration, Tied Foreign Aid and the Welfare State, July 2005

1498 Agata Antkiewicz and John Whalley, BRICSAM and the Non-WTO, July 2005

1499 Petr Hedbávný, Ondřej Schneider and Jan Zápal, A Fiscal Rule that has Teeth: A Suggestion for a 'Fiscal Sustainability Council' underpinned by the Financial Markets, July 2005

1500 J. Atsu Amegashie and Marco Runkel, Sabotaging Potential Rivals, July 2005

1501 Heikki Oksanen, Actuarial Neutrality across Generations Applied to Public Pensions under Population Ageing: Effects on Government Finances and National Saving, July 2005

1502 Xenia Matschke, Costly Revenue-Raising and the Case for Favoring Import-Competing Industries, July 2005

1503 Horst Raff and Nicolas Schmitt, Why Parallel Trade may Raise Producers Profits, July 2005

1504 Alberto Bisin and Piero Gottardi, Efficient Competitive Equilibria with Adverse Selection, July 2005 
1505 Peter A. Zadrozny, Necessary and Sufficient Restrictions for Existence of a Unique Fourth Moment of a Univariate GARCH(p,q) Process, July 2005

1506 Rainer Niemann and Corinna Treisch, Group Taxation, Asymmetric Taxation and Cross-Border Investment Incentives in Austria, July 2005

1507 Thomas Christiaans, Thomas Eichner and Ruediger Pethig, Optimal Pest Control in Agriculture, July 2005

1508 Biswa N. Bhattacharyay and Prabir De, Promotion of Trade and Investments between China and India: The Case of Southwest China and East and Northeast India, July 2005

1509 Jean Hindriks and Ben Lockwood, Decentralization and Electoral Accountability: Incentives, Separation, and Voter Welfare, July 2005

1510 Michelle R. Garfinkel, Stergios Skaperdas and Constantinos Syropoulos, Globalization and Domestic Conflict, July 2005

1511 Jesús Crespo-Cuaresma, Balázs Égert and Ronald MacDonald, Non-Linear Exchange Rate Dynamics in Target Zones: A Bumpy Road towards a Honeymoon - Some Evidence from the ERM, ERM2 and Selected New EU Member States, July 2005

1512 David S. Evans and Michael Salinger, Curing Sinus Headaches and Tying Law: An Empirical Analysis of Bundling Decongestants and Pain Relievers, August 2005

1513 Christian Keuschnigg and Martin D. Dietz, A Growth Oriented Dual Income Tax, July 2005

1514 Fahad Khalil, David Martimort and Bruno Parigi, Monitoring a Common Agent: Implications for Financial Contracting, August 2005

1515 Volker Grossmann and Panu Poutvaara, Pareto-Improving Bequest Taxation, August 2005

1516 Lars P. Feld and Emmanuelle Reulier, Strategic Tax Competition in Switzerland: Evidence from a Panel of the Swiss Cantons, August 2005

1517 Kira Boerner and Silke Uebelmesser, Migration and the Welfare State: The Economic Power of the Non-Voter?, August 2005

1518 Gabriela Schütz, Heinrich W. Ursprung and Ludger Wößmann, Education Policy and Equality of Opportunity, August 2005

1519 David S. Evans and Michael A. Salinger, Curing Sinus Headaches and Tying Law: An Empirical Analysis of Bundling Decongestants and Pain Relievers, August 2005

1520 Michel Beine, Paul De Grauwe and Marianna Grimaldi, The Impact of FX Central Bank Intervention in a Noise Trading Framework, August 2005

1521 Volker Meier and Matthias Wrede, Pension, Fertility, and Education, August 2005 
1522 Saku Aura and Thomas Davidoff, Optimal Commodity Taxation when Land and Structures must be Taxed at the Same Rate, August 2005

1523 Andreas Haufler and Søren Bo Nielsen, Merger Policy to Promote 'Global Players'? A Simple Model, August 2005

1524 Frederick van der Ploeg, The Making of Cultural Policy: A European Perspective, August 2005

1525 Alexander Kemnitz, Can Immigrant Employment Alleviate the Demographic Burden? The Role of Union Centralization, August 2005

1526 Baoline Chen and Peter A. Zadrozny, Estimated U.S. Manufacturing Production Capital and Technology Based on an Estimated Dynamic Economic Model, August 2005

1527 Marcel Gérard, Multijurisdictional Firms and Governments' Strategies under Alternative Tax Designs, August 2005

1528 Joerg Breitscheidel and Hans Gersbach, Self-Financing Environmental Mechanisms, August 2005

1529 Giorgio Fazio, Ronald MacDonald and Jacques Mélitz, Trade Costs, Trade Balances and Current Accounts: An Application of Gravity to Multilateral Trade, August 2005

1530 Thomas Christiaans, Thomas Eichner and Ruediger Pethig, A Micro-Level 'Consumer Approach' to Species Population Dynamics, August 2005

1531 Samuel Hanson, M. Hashem Pesaran and Til Schuermann, Firm Heterogeneity and Credit Risk Diversification, August 2005

1532 Mark Mink and Jakob de Haan, Has the Stability and Growth Pact Impeded Political Budget Cycles in the European Union?, September 2005

1533 Roberta Colavecchio, Declan Curran and Michael Funke, Drifting Together or Falling Apart? The Empirics of Regional Economic Growth in Post-Unification Germany, September 2005

1534 Kai A. Konrad and Stergios Skaperdas, Succession Rules and Leadership Rents, September 2005

1535 Robert Dur and Amihai Glazer, The Desire for Impact, September 2005

1536 Wolfgang Buchholz and Wolfgang Peters, Justifying the Lindahl Solution as an Outcome of Fair Cooperation, September 2005

1537 Pieter A. Gautier, Coen N. Teulings and Aico van Vuuren, On-the-Job Search and Sorting, September 2005

1538 Leif Danziger, Output Effects of Inflation with Fixed Price- and Quantity-Adjustment Costs, September 2005 
1539 Gerhard Glomm, Juergen Jung, Changmin Lee and Chung Tran, Public Pensions and Capital Accumulation: The Case of Brazil, September 2005

1540 Yvonne Adema, Lex Meijdam and Harrie A. A. Verbon, The International Spillover Effects of Pension Reform, September 2005

1541 Richard Disney, Household Saving Rates and the Design of Social Security Programmes: Evidence from a Country Panel, September 2005

1542 David Dorn and Alfonso Sousa-Poza, Early Retirement: Free Choice or Forced Decision?, September 2005

1543 Clara Graziano and Annalisa Luporini, Ownership Concentration, Monitoring and Optimal Board Structure, September 2005

1544 Panu Poutvaara, Social Security Incentives, Human Capital Investment and Mobility of Labor, September 2005

1545 Kjell Erik Lommerud, Frode Meland and Odd Rune Straume, Can Deunionization Lead to International Outsourcing?, September 2005

1546 Robert Inklaar, Richard Jong-A-Pin and Jakob de Haan, Trade and Business Cycle Synchronization in OECD Countries: A Re-examination, September 2005

1547 Randall K. Filer and Marjorie Honig, Endogenous Pensions and Retirement Behavior, September 2005

1548 M. Hashem Pesaran, Til Schuermann and Bjoern-Jakob Treutler, Global Business Cycles and Credit Risk, September 2005

1549 Ruediger Pethig, Nonlinear Production, Abatement, Pollution and Materials Balance Reconsidered, September 2005

1550 Antonis Adam and Thomas Moutos, Turkish Delight for Some, Cold Turkey for Others?: The Effects of the EU-Turkey Customs Union, September 2005

1551 Peter Birch Sørensen, Dual Income Taxation: Why and how?, September 2005

1552 Kurt R. Brekke, Robert Nuscheler and Odd Rune Straume, Gatekeeping in Health Care, September 2005

1553 Maarten Bosker, Steven Brakman, Harry Garretsen and Marc Schramm, Looking for Multiple Equilibria when Geography Matters: German City Growth and the WWII Shock, September 2005 